\title{
Influence of Injection Moulding Parameters on Electrical Conductivity of Polypropylene-Graphite Composite Bipolar Plates for Hydrogen Fuel Cells
}

\author{
DANIIEL SERBAN* \\ University Politehnica Bucharest, 313 Splaiul Independentei, 060042, Bucharest, Romania
}

\begin{abstract}
News on Green Energy and Green Hydrogen is spread on popular and academic media. When energy is obtained from sunlight, wind or water, we call it Green Energy. When hydrogen is obtained from electrolysis with Green Energy, we call it Green Hydrogen. Hydrogen Fuel Cells are electrochemical devices that convert hydrogen and oxygen's chemical energy into electricity and heat energy with high efficiency and contribute to the decarbonisation of the power supply. Bipolar plates, essential components of the fuel cells, made in polymer-carbon composites, are an economical alternative to the stainless steel, titan and graphite, traditional materials. Our experiments have used a polypropylene matrix filled with graphite with a total inorganic content of $87 \%$, which contributes to high electrical and thermic conductivity but strongly influences the viscosity, flow, pressures, temperatures, and is then challenging to process. Injection Moulding of thermoplastics is a technology widespread in all fields of activities and has considerable potential. In this paper, the experiments' design is highlighted in choosing the factors. A debate regarding the filling, packing, holding pressures, and the last decades' approach and optimisation of injection moulding parameters with the Taguchi Method is presented. Conclusions on the injection moulding process of the bipolar plate made of a polypropylene-graphite composite, the parameters' influence with direct effects on the fuel stack's performance are presented. The combined melt and mould temperatures influence most electrical conductivity by better contacting the electrically conductive particles through the polymer's melted layer. The injection pressure influences the mass and thickness of the product and the electrical conductivity by better packing. Furthermore, we suggest an adapted formula to predict the injection pressure considering the inorganic content and the process temperatures in agreement with the experiments.
\end{abstract}

Keywords: injection moulding, polypropylene-graphite composite, hydrogen fuel cell, Taguchi Method

\section{Introduction}

The bipolar plates are components of the fuel cell stacks, representing about $60 \%$ of the total weight and $40 \%$ of total costs. The functions are to distribute the fuel uniformly (the hydrogen at anode and oxygen at the cathode) and provide the electrical and thermal connection between the cells. Good electrical conductivity is required to reduce power losses. Bipolar plates made of stainless steel, titan or graphite require expensive surface treatments to reduce corrosion and permeability. Thus, polymericcarbon composites are an economical alternative.

A polymer may be defined as a macromolecule product built by repeating small, simple chemical units (monomers). For example, polypropylene (PP), also known as polypropene, is a thermoplastic polymer used in various applications and is produced via polymerisation from the monomer propylene, primarily based on a method now known as Ziegler-Natta catalyst [1]. Thermoplastic materials are obtained from polymers and are shaped at temperatures when they become plastics and get the final product solid configuration by cooling. Glass-transition temperature indicates the range of temperatures over which the glass transition occurs, from a brittle into a viscous state. For crystalline polymers, the glass-transition temperature is lower than the melting temperature of the crystalline state. At higher temperatures, the material can degrade.

*email: dserban@ddplast.ro

(iD ORCID ID https://orcid.org/0000-0002-8361-212X 
Thermogravimetric analysis (TGA) is a process that continuously measures sample weight when heated at a linear rate.TGA can help to evaluate thermal degradation behaviour. Thermoplastics are processed mainly by extrusion, injection moulding, vacuum forming, compression, blow moulding [2]. The proprieties of a polymer can be improved by incorporating additives like fillers, colourants, flameretarders, anti-ageing, to name a few. A polymeric composite consists of a polymer matrix to which fillers are added. The mixing methods may vary, extrusion, Banbury mixing, roll-mill mixing, melt compounding or solution compounding. The fillers do not interact with the matrix. For example, carbon black is a powerful reinforcing filler that contributes to the composite's good thermal and electrical conductivity. Graphite fillers improve dimensional stability, thermal and electrical conductivity [1].

The majority works theoretically and experimentally evaluated the percolation threshold, thermal and electrical conductivity, aggregation, structure for composites with inorganic content up to $10 \%$. In addition, influences of fillers like carbon nanotubes (CNT's), carbon nanostructures (CBN's), graphene and derivates, available at high costs, were evaluated. The review of conductive composites highlighted the analyses used mostly of thermosets (epoxy) matrices, thermoplastics polycarbonate, polyethylene a maximum conductivity of $700 \mathrm{~S} / \mathrm{m}$ obtained for a PPO matrix filled with 50wt\% MWCNT, and 20S/m for a polypropylene filled 9wt\% MWCNT (multi-wall carbon nanotubes [3]. The US Department of Energy recommends a conductivity of $100 \mathrm{~S} / \mathrm{cm}$ for bipolar plates materials.

A high proportion, usually over $70 \%$ of graphite, is added to a thermoplastic polymer to obtain a good electrical conductivity of a composite for injection moulding bipolar plates at an industrial scale at economical costs. Nevertheless, in this range, there are few works disseminating results. Good electrical conductivities of $27 \mathrm{~S} / \mathrm{cm}$ for bipolar plates were obtained by solution blending polypropylene, graphite and carbon black with a total inorganic content of $80 \%$ [4]. Thermogravimetry analyses on a similar polypropylene composite with high graphite content of $60 \%$ demonstrated a minor degradation step up to $480^{\circ} \mathrm{C}$; after that, a sharp weight loss was observed [4]. Derieth et al. demonstrated better results of about $100 \mathrm{~S} / \mathrm{cm}$ of bulk conductivity for smaller flakes particles of graphite at a $78 \%$ load. However, they observed that spherical morphology enables a higher filling load and then conductivity. The pressure applied to the measurement sandwich influenced very little bulk conductivity, but an important influence was observed for volume conductivities [5]. Polypropylene melt-mixed in a twin-extruder with expanded graphite powder with loads from $10 \%$ to $80 \%$ demonstrated increased thermal and electrical conductivity with the filler content. For example, the electrical conductivity: $0.6 \mathrm{~S} / \mathrm{cm}$ for $10 \mathrm{wt} \%$ load to $15.9 \mathrm{~S} / \mathrm{cm}$ for PP composite with $80 \mathrm{wt} \%$ graphite. The contents were confirmed by thermogravimetric analyses [6].

The inorganic content influences the viscosity of the composite. Therefore, higher temperatures and injection pressures are required for injection moulding. Higher temperatures may concern the degradation of the product. Thermogravimetric analyses demonstrated for polypropylene that a maximum degradation rate at a recorded temperature ranges from 435 to $457^{\circ} \mathrm{C}$ [7]. Chipara et al. demonstrated that the temperature at which the mass loss rate is maximum is increased with the concentration of carbon fibres dispersed within the polypropylene matrix, and it was measured in the range of 460 to $470{ }^{\circ} \mathrm{C}$ for composites with up to $20 \%$ carbon nanofibers [8].

In previous experiments with a compound $87 \%$ graphite in PP, the author observed on the injection moulded bipolar plates a variance of the performance when tested in fuel cell stacks. Then, we planed new experiments to explore the improvements in performance by analysing the influence of surface microstructure on the electrical contact resistance, effect of inorganic content, the hydrogen supply and presented here in this paper, optimise and effect of the injection moulding parameters.

The Taguchi approach of Design of Experiments has been the popular product and process improvement tool for engineering and scientific professionals since its introduction in the USA in the 1980s. Simulating flow software can optimise the injection moulding parameters against trial and error, statistical methods on the Design of Experiments. However, flow simulation software needs accurate rheological material data, unavailable for our experiments material. Thus, we chose a method that can be introduced to small companies at no high costs. This paper proposes a simple formula to predict the 
injection pressure of a highly filled polymeric composite. The formula is adapted on an experimentally developed equation for the calculus of the viscosity of a composite filled with carbon black and considers the influence of process temperatures. The Taguchi method performed to optimise the injection moulding parameters for better conductivity of a polymer composite bipolar plate and the influence of the bipolar plate on the power efficiency of the hydrogen-air PEM fuel cell are presented.

\section{Materials, equipment and methods}

\subsection{Materials}

First, the bipolar plate was injection moulded in a PP, Polypropylene grade J1100 from Rompetrol (MFR of 26,0- 30,0 g/10 min, $230^{\circ} \mathrm{C}, 2.16 \mathrm{~kg} / \mathrm{ISO} 1133 \mathrm{~B}$ ) for evaluation of the injection moulding parameters: the temperature at injection moulding nozzle, the temperature of the mould cavity, injection pressure and cavity pressure.

Then, we performed the experiments of injection moulding the bipolar plates in a polypropylene graphite composite $(\mathrm{PP}+87 \mathrm{GR})$ with an $87 \mathrm{wt} \%$ inorganic content, purchased from Centre of Fuel Cell Technology ZBT GmbH Duisburg. The material is suitable for bipolar plates for low-temperature operated fuel cells (under $120^{\circ} \mathrm{C}$ ). The compound is made in a twin-screw extruder and granulated in pellets form with maximum dimension as of four-millimetre diameter and $12 \mathrm{~mm}$ length as shown in Figure 1a. Derieth et al. evidenced the influence of the particle dimension on the bulk-conductivity: about $98 \mathrm{~S} / \mathrm{cm}$ for particles of $5 \mu \mathrm{m}$ diameter and particles of $10 \mu \mathrm{m}$ a bulk-conductivity of about 58 $\mathrm{S} / \mathrm{cm}$ [5]. An SEM analysis of the internal microstructure of the compound observed that the layer of 200 to $400 \mu \mathrm{m}$ closed to the mould surface presented lower conductivity because the graphite flakes were oriented perpendicular to the current flow. The core presented an orientation of the graphite flakes in the sense of the current flow in the fuel cell and a better electrical conductivity [5].

Thermogravimetric analysis (TGA) of the composite PP+87GR performed at Advanced Polymer Materials Group confirmed a high rate of degradation in $430^{\circ} \mathrm{C}$ to $490^{\circ} \mathrm{C}$ and $86.6 \%$ inorganic content (Figure 1b).

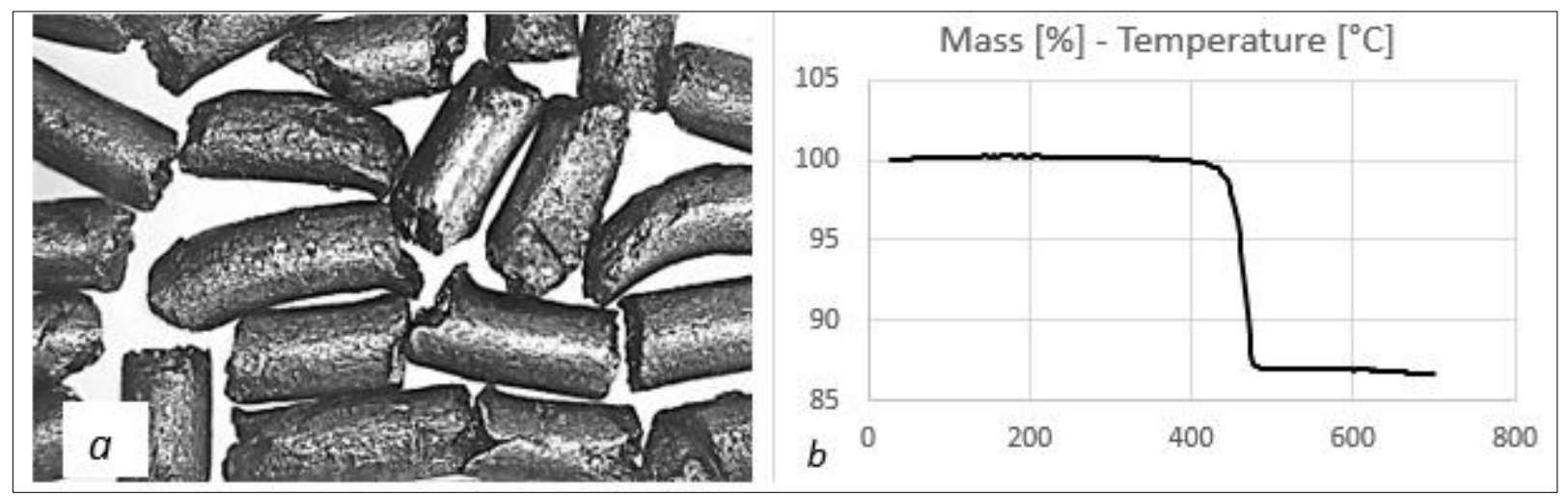

Figure 1a. Composite pellets samples; b. TGA analyse on a ten ${ }^{\circ} \mathrm{C} / \mathrm{min}$ profile

\subsection{Equipment}

The injection moulding machine, Arburg Allrounder 221-75-350 equipped with Polytronica Controller one-stage system with switch-over on stroke and time which can deliver the same holding pressure as the injection pressure and on which the parameters can be set as follows: maximum hydraulic ram injection pressure - $p_{h} 135$ bar, specific injection pressure - $p 1090 \mathrm{bar}$, times - [s], strokes - [mm], speeds - in percentage [\%], 100\% corresponding to a maximum speed of $100 \mathrm{~mm} / \mathrm{s} \mathrm{or} 64 \mathrm{~cm}^{3} / \mathrm{s}$ [9]. The cavity pressure was measured with a Multi-Process Controller DME 4000 and a sensor DME 405C placed on the cathode side of the bipolar plate cavity mould, made in Aluminium EN 7075, and electrically heated. The model of the bipolar plate has a hydrogen circuit at the anode and an oxygen circuit at the cathode and has a size of $55 \times 55 \times 4 \mathrm{~mm}^{3}$. For the electrical resistance measurements, a 
Direct Current Source (30 Volt, 10 Amper) was used, and each sample was measured in a stack at a load of ten daN. The voltage and current were recorded with the help of a multifunction monitor. The thickness of the bipolar plates was measured with a digital calliper. The fuel cell stack was supplied hydrogen from a hydride cartridge at 0.3 bar and forced air with a fan.

\subsection{Estimate the injection pressure method}

Dobrescu et al. [10] developed formula (1) for composites low-density polyethylene - carbon black:

$$
\eta_{k}=\eta_{p}\left(1+a c^{b}\right)
$$

where: $\eta_{k}$ is the viscosity of the composite [Pas]; $\eta_{\mathrm{p}}$ is the viscosity of the matrix polymer [Pas]; $a, b$ are coefficients experimentally developed, and $c$ represents the parts of filler. Viscosity is not a direct parameter the operator can set on the equipment controller; therefore, based on equation (1), here we introduce an adapted formula (2) by considering the influence of melts and mould temperatures for the estimation of the hydraulic injection pressure:

$$
p_{h k}=p_{h p}\left(1+a c^{b} / d^{f}\right)
$$

where: $p_{h k}$ is the hydraulic injection pressure of the composite, $p_{h p}$ the matrix polymer's hydraulic injection pressure, $a=0.297$ and $b=1.3$, are experimentally evaluated by Dobrescu et al. [10], $f=2.5$, coefficient experimentally evaluated by considering the influence of the combined temperatures of the melt at the nozzle and mould temperature, $d$, calculated with equation (3):

$$
d=\left(T_{N k}+T_{C k}\right) /\left(T_{N p}+T_{C p}\right)
$$

where: $T_{N k}$ is the (nozzle set) temperature of the composite, $T_{N p}$ is the (nozzle set) temperature of the polymer, $T_{C k}$ is the mould cavity temperature for the composite, and $T_{C p}$ is the mould cavity temperature for the polymer, as recommended by suppliers. It is the place to clarify the terms regarding pressures related to the injection phases. The pressures set on machine controllers: maximum injection pressure controlled by speeds, $p_{h}$-hydraulic pressure or $p$ - specific pressure on modern controllers, hydraulic or specific holding pressures controlled by time. Moreover, we have the pressures related to the mould cavity and mentioned by literature, papers, flow simulation software: (mould) filling pressure, (mould) packing pressure measured on sensors placed into the mould cavities. The cavity pressure might differ with the sensor's position, lower at the end of the flow. In our experiment, we use the terms hydraulic injection pressure $p_{h}$, specific injection pressure $p$ (as the hydraulic pressure multiplied with the intensification ratio) and mould cavity pressure $p_{c}$ (as measured with the DME sensor placed in the mould manufactured for the injection moulds tests), as shown in Figure 2a. We consider packing pressure controlled by time as holding pressure, and when not mentioning control, we consider it the second stage phase injection pressure.

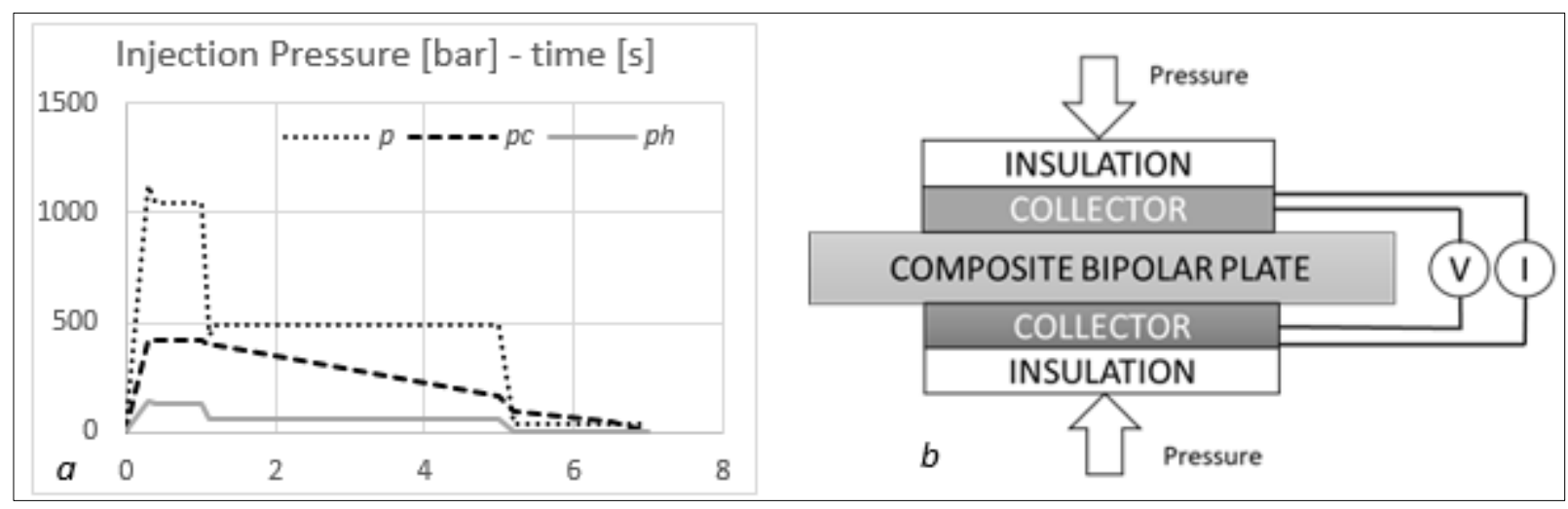

Figure 2a. Hydraulic pressure (set) - $p_{h}$, cavity mould pressure (measured) - $p_{c}$, specific pressure $p ; \mathrm{b}$. measuring electrical resistance layout 


\subsection{Measuring the electrical conductive proprieties of the moulded bipolar plates}

We measured the electrical resistance through-plane of the bipolar plates in an assembly to compare the results shown in Figure $2 b$ at a ten daN load. Then, four bipolar plates of each experiment were assembled in a hydrogen-air (forced) fuel cell stack and tested at room temperature; hydrogen supplied from an $\mathrm{AB}_{5}$ metal hydride cartridge at $0.03 \mathrm{MPa}$ pressure and forced air with a fan help. The measurement of the fuel cell efficiency equipped with the bipolar plates of the four experiments directly indicates the influence of the injection moulding parameters.

\subsection{Taguchi process optimisation method}

The Taguchi Method utilises the conventional tools, simplifying them by identifying the guidelines for the experiment layout and the result analysis. The Taguchi method consists of (a) Select Project and Form Team, (b) Conduct Experiment Planning Discussion, (c) Design Experiment (Layout/Test Plan), (d) Carry Out Planned Experiments and Collect Results, (e) Analyse Results, (f) Observation Summary, (g) Validate Improvement. The concepts are: (1) quality should be designed into the product and not inspected into it, (2) quality is best achieved by reducing the deviation from a target, (3) the cost of quality is appreciated as a function of the deviation from the standard, and (4) the losses should be measured system-wide [11]. In the injection moulding process, quality characteristics such as reject rate, flash, or porosity have traditionally been measured Taguchi method uses Smaller-the-Better, Nominal-the-Better and Larger-the-Better [11,12].

\subsubsection{Select Project and form team}

Project: Optimisation of injection moulding parameters of a bipolar plate for a Proton-Exchange Membrane (or Polymer Electrolyte Membrane - PEM) hydrogen fuel cell. The study's goal consisted of analysing the influence of the injection moulding parameters on the electrical conductivity of the bipolar plate and the performance of the PEM hydrogen fuel five cell assembly.

Form Team: Any Design of Experiments (DOE) procedure must be backed by a complete knowledge of the technology underlying principles, which helps understand the phenomena and is essential in interpreting the analysis. The team should have between 2 and 15 members. The machine operator and the production staff should be part of the team.

Team, 3 Members: Machine Operator, The Author (Leader and Facilitator) and we considered as a third "member" the References (Injection Moulding Machine Controller Polytronica Operation Manual, Literature, Taguchi Papers, open-access Flow Simulation Software documentation).

\subsubsection{Experiment planning discussions}

Objective: To investigate the interaction between packing and electrical conductance of the bipolar plate and its influence on the PEM hydrogen fuel cell's performance.

Identify the quality characteristics: measured the parts' weight, the resistance (calculate conductance), and the fuel cell efficiency performance; strategy: Larger -the-Better.

\subsubsection{Factors}

We analysed the literature content (period 1982 - 2020, in Table 1) and the Taguchi method applied to injection moulding (2004 - 2020, in Table 2) by counting the number of times a parameter is mentioned. When the pack pressure was mentioned as the second stage, it was considered an Injection pressure - fill \& pack, and when the pack was referred to as the third stage controlled by time, it was considered a holding pressure.

Table 1. Quantitative analysis of the literature content - The number of times a parameter related to the injection unit and mould mentioned in literature [1, 14-20]

\begin{tabular}{|c|c|c|c|c|c|c|c|c|c|c|}
\hline Parameters (term) & Nr. & Nr. & Nr. & Nr. & Nr. & Nr. & Nr. & Nr. & Total & Rank \\
\hline Mould temperature & 46 & 37 & 65 & 300 & 140 & 89 & 8 & 89 & 774 & 3 \\
\hline
\end{tabular}




\begin{tabular}{|c|c|c|c|c|c|c|c|c|c|c|}
\hline Injection pressure - fill & 73 & 6 & 120 & 280 & 85 & 83 & 36 & 184 & 867 & 2 \\
\hline Cooling / cure time & 29 & 5 & 29 & 104 & 37 & 25 & 66 & 18 & 313 & 7 \\
\hline Packing/holding pressure & 8 & 0 & 26 & 145 & 165 & 82 & 126 & 84 & 636 & 4 \\
\hline Melt / barrel temperature & 152 & 40 & 59 & 375 & 53 & 120 & 158 & 85 & 1042 & 1 \\
\hline Back pressure & 72 & 3 & 51 & 109 & 64 & 40 & 15 & 68 & 422 & 5 \\
\hline Injection speed & 69 & 3 & 13 & 91 & 76 & 23 & 29 & 107 & 411 & 6 \\
\hline Packing / holding time & 2 & 0 & 6 & 29 & 8 & 43 & 32 & 3 & 123 & 9 \\
\hline Injection time & 13 & 3 & 8 & 34 & 20 & 6 & 28 & 11 & 123 & 10 \\
\hline Reference & {$[14]$} & {$[1]$} & {$[15]$} & {$[16]$} & {$[17]$} & {$[18]$} & {$[19]$} & {$[20]$} & & \\
\hline Year of publication & 1982 & 1989 & 1996 & 2000 & 2004 & 2010 & 2013 & 2020 & & \\
\hline
\end{tabular}

Table 2. Quantitative analysis of the parameters related to the injection unit and mould - factors contribution rank according to Taguchi analysis works [12, 13, 21-24]

\begin{tabular}{|c|c|c|c|c|c|c|c|c|c|}
\hline Parameters (Factors) & Rank & Rank & Rank & Rank & Rank & Rank & AV & N/AV & Rank \\
\hline Mould temperature & 1 & 3 & 4 & 3 & 1 & 4 & 2.67 & 2.25 & 1 \\
\hline Injection pressure - fill \& pack & & & 1 & & 3 & & 2 & 1 & 5 \\
\hline Cooling / cure time & 4 & 2 & & & & 3 & 3 & 1 & 5 \\
\hline Packing/holding pressure & 6 & 1 & & 4 & & 1 & 3 & 1.33 & 2 \\
\hline Melt / barrel temperature & 5 & & 2 & 2 & 4 & & 3.25 & 1.23 & 4 \\
\hline Injection speed & 3 & & 3 & 1 & & & 2.33 & 1.28 & 3 \\
\hline Packing/holding time & 2 & & & & & 2 & 2 & 1 & 5 \\
\hline Injection time & & & & & 2 & & 2 & 0.5 & 6 \\
\hline Noise Factors & & & & 2 & & & & & \\
\hline Levels & 3 & 2 & 3 & 2 & 2 & & & & \\
\hline Measurements & 3 & 2 & 2 & 2 & 1 & & & & \\
\hline Reference & {$[12]$} & {$[13]$} & {$[21]$} & {$[22]$} & {$[23]$} & {$[24]$} & & & \\
\hline Year of publication & 2004 & 2010 & 2011 & 2013 & 2016 & 2020 & & & \\
\hline
\end{tabular}

The coefficient N/AV representing Sum of apparitions of the term/ Average Rank, presented in Table 2, do not confirm the Ranks according to the literature presented in Table 1, the packing/holding, overpasses the injection/filling pressure and mould temperature overpasses the melt temperature. Injection pressure is the fifth, injection speed is the third. It shows the approach of the last decade, influenced by the flow simulation software analyses.

\section{Filling pressure and packing pressure terms in injection moulding technology}

Literature. Filling: the injection unit delivers a pre-set amount of molten polymer to the mould tool; Packing and Solidification: Under pressure, once the material is in the tool, it fills the cavity (mould packing), then the part cooled and is finally ejected. The packing stage aims to add extra material to compensate for the shrinkage caused by the decreasing density of the solidifying polymer [17]. During the mould cavity filling, high injection pressures maintain the desired filling speed. Once the mould cavity is complete, this high pressure may not be necessary or desirable; a lower, second stage pressure may follow a high first stage pressure. At a certain point in the injection moulding stroke, when the mould is almost complete or the gate freezes, the resistance to flow becomes high and, it becomes difficult for the screw to maintain the desired rate. The Velocity Pressure Transfer (VPT) is when control shifts from velocity to pressure [1]. Seres claims that the transition from filling the mould cavity to the packing (also known as the transition from the first stage to the second stage) is performed differently in injection with a material cushion versus without a material cushion (switch-over on the maximum stroke). The packing phase starts with the end of filling and ends with the gate freezing point [2]. A three-stage system introduces the terms filling (first stage), packing (second stage) and holding (third stage). The first injection pressure completes the filling and packing phases; the holding pressure executes the third stage.

Flow simulation software. When comparing the pressures between the moulding machine and the simulation, the plastic pressure should be measured directly and not calculated as the hydraulic pressure multiplied by the intensification ratio whenever possible. Differences between simulated and real 
pressure can appear when data is not dependent on viscosity [25]. Eventually, accurate rheologic data are a must; data collection is a hard and expensive job.

For the polypropylene - graphite composite is not available rheologic data for a reliable flow simulation. Therefore, we have chosen the L4 orthogonal array with a Larger-the-Better strategy to optimise the process and an adapted formula for estimating the injection pressure. We used the terms hydraulic injection pressure $p_{h}$, specific injection pressure $p$ (as the hydraulic pressure multiplied with the intensification ratio) and mould cavity pressure $p_{c}$ (as measured with the DME sensor placed in the mould manufactured for the injection moulds tests).

Machine controllers. In modern injection moulding machines, the operator can set multi-stage pressures, maximum injection pressure, injection speeds, holding pressures, and times. The switch-over point (Velocity Pressure Transfer) can be set on screw position, hydraulic pressure or specific pressure, cavity pressure (optional), or time [26-28]. Machine Constructors like Fanuc use the terms maximum injection pressure and maximum pack pressure [29].

\subsubsection{Levels}

Material supplier recommendation guideline for injection moulding of composites with high graphite content: the shot weights: $30-70 \%$ of the maximum available on the injection unit, generous open machine and mould nozzle, large cross-section runners and gate, high injection speed, holding pressure: $2 / 3$ of the maximum injection pressure, holding Time: $1.25 \mathrm{~s} / \mathrm{mm}$ of thickness, temperatures: mould 70 $90^{\circ} \mathrm{C}$, barrel 220 to $360^{\circ} \mathrm{C}$ (to the nozzle of the injection unit). This study indicates the equipment, injection unit cylinder and mould temperatures and not of the compound melt. In Figure 3 are presented the injection moulding parameters and the location where they are set or measured. No polymer is infinitely stable at the processing temperatures, so that it may concern changing proprieties and degradation [14]. TGA analyses performed at Advanced Polymer Materials Group on our experiments material observed the composite degradation high rate above $430^{\circ} \mathrm{C}$. Results are confirmed by Halasz et al. [7] or Chipara et al. [8] on polypropylene-carbon compounds TGA. Our tests with injection moulding the bipolar plate in polypropylene evidenced the maximum hydraulic injection pressure, $p_{h p}$ of $30 \mathrm{bar}$, a specific pressure of 242.22 bar and a measured (average) cavity pressure $p_{c} 207.6$ bar at a barrel nozzle temperature set $220^{\circ} \mathrm{C}$, mould temperature $30^{\circ} \mathrm{C}$.

Valero et al. [20] recommend for PP melt temperature of 200 to $290^{\circ} \mathrm{C}$ and affirm that melt temperature results from screw rotation speed, back pressure and injection unit temperature. Seres [2], Whelan [14], Rosato et al. [16] indicate a lower effect of the injection rotational speed and a significant effect of the shear rate heating and barrel temperatures. Goodship recommends for PP an ascending profile of cylinder temperatures from 220 to $290^{\circ} \mathrm{C}$ [17].

\section{The decision on choosing the factors and level}

To optimise the process and analyse the influence of the injection moulding parameters on the resistance of the bipolar plate (and on the fuel cell performance), on a minimal design of experiments, a Taguchi L4 orthogonal array, three factors with two levels was chosen.

Table 3. Procedure on choosing the levels of the factor's temperature and pressure

\begin{tabular}{|c|c|c|}
\hline Factor & $\begin{array}{c}\text { Composite Supplier } \\
\text { Recommendation }\end{array}$ & Observation \\
\hline $\begin{array}{c}\text { Set Temperature at } \\
\text { Nozzle }\left(T_{N}\right)\end{array}$ & $T_{N}=300 \div 360^{\circ} \mathrm{C}$ \\
AVERAGE $T_{N}=330^{\circ} \mathrm{C}$ & For polypropylene, the AVERAGE Barrel's Nozzle Temperature for \\
PP is of about $220^{\circ} \mathrm{C} ;$
\end{tabular}


From 30 experiments, we analysed the representative 20 experiments $(5$ samples for each experiment). Table 3 is presented the procedure for choosing the levels of factors: $T_{N}$ - barrel nozzle set temperature, 320-340 [ $\left.{ }^{\circ} \mathrm{C}\right] \& T_{C}$ - mould temperature, 70-80 [ $\left.{ }^{\circ} \mathrm{C}\right], p_{h^{-}}$hydraulic injection pressure $100-$ $130 \mathrm{bar}$, and $t_{H^{-}}$holding time 4-8 s. Table 4 presents the order of experiments, factors and levels. Pressures are indicated in bars as they can be set and measured.

\subsection{Measurements concept}

We considered simple methods for evaluating the influence of the injection moulding parameters on the electrical conductivity of the bipolar plates: measuring the performance of the fuel cell stack, the product and standard available equipment. The units are indicated as they can be set or read on equipment controllers.

\section{Results and discussions}

\subsection{Results, Taguchi and ANOVA analyses}

The Taguchi method uses a statistical measure of performance called signal-to-noise SN, for LargerThe-Better, calculated with formulas (3) and (4) a function of Mean Sum of Squares Deviation of the measured values of the experiment $\left(y_{i}\right)$, MSD. The Taguchi and ANOVA analyses calculations were made with a standard commercially licenced spreadsheet software.

$$
\begin{aligned}
& M S D=n^{-1} \sum_{1}^{n} \frac{1}{y_{i}^{2}} \\
& S N=-10 \log (M S D)
\end{aligned}
$$

Table 4. Order of experiments, L4 orthogonal array, 3 factors, 2 levels, SET on controller values

\begin{tabular}{|c|c|c|c|c|c|c|}
\hline \multicolumn{2}{|c|}{} & \multicolumn{5}{|c|}{3 FACTORS - 2 LEVELS } \\
\hline Exp. & Order & \multicolumn{2}{|c|}{$T_{N}+T_{C}\left[{ }^{\circ} \mathrm{C}\right]$} & $p_{h}$ - Hydraulic Pressure [bar] & \multicolumn{2}{c|}{$t_{H}$-Holding Time [s] } \\
\cline { 3 - 6 } No. & No. & $T_{N} 320+T_{C} 70$ & $T_{N} 340+T_{C} 80$ & 100 & 130 & 4 \\
\hline 1 & 1 & $320+70$ & 100 & 4 \\
\hline 2 & 2 & $320+70$ & 130 & 8 \\
\hline 3 & 3 & $340+80$ & 100 & 8 \\
\hline 4 & 4 & $340+80$ & 130 & 4 \\
\hline
\end{tabular}

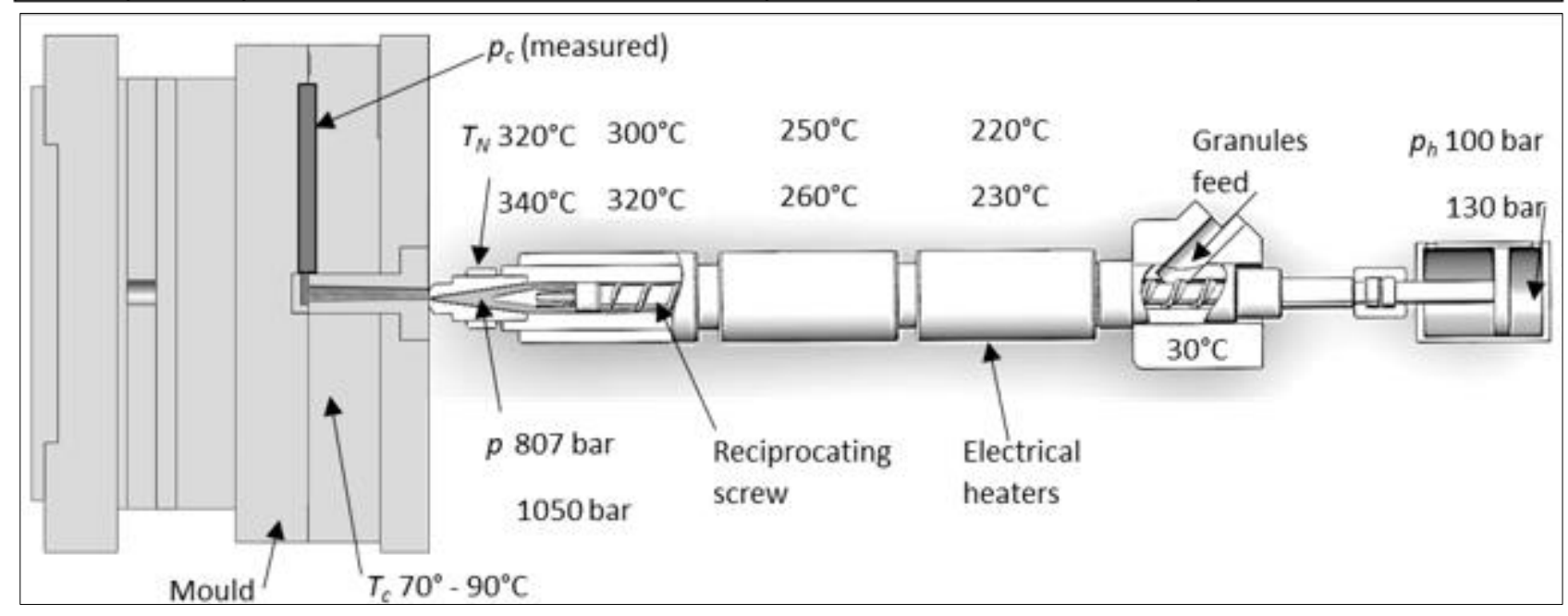

Figure 3. Process parameters. Profile of temperatures set on the injection barrel. Set hydraulic pressure in the installation - $p_{h}$, calculated specific pressure in the front of the screw - $p$, measured pressure in the cavity $-p_{c}$ 


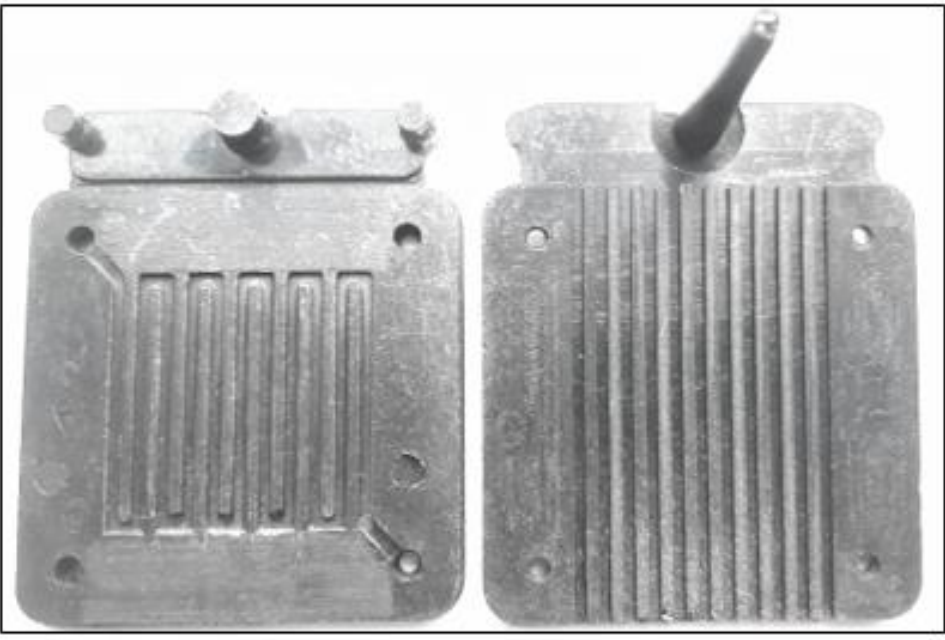

a

b

Figure 4. Samples of Experiment no. 3, a) complete injection anode side view,

b) complete injection cathode side view including sprue, runner and gate

Process parameters are presented in Figure 3, and injection moulded samples of experiment no. 3 are shown in Figure 4.

\subsection{Analyses of mass and thicknesses measurements}

In Figure 4 are presented samples of experiment no. 3; the mass has been measured on a complete injection shot, including sprue, runner and gate (to not influence the results by different gate cuts). The bipolar plates have $55 \mathrm{~mm}$ x $55 \mathrm{~mm}-4.2 \mathrm{~mm}$ with a $32 \mathrm{~mm}$ x $32 \mathrm{~mm}$ gas active area at the anode and eleven channels $55 \mathrm{~mm} \times 1.5 \mathrm{~mm}-1 \mathrm{~mm}$ at the cathode. Figure 5 are presented the mass and thickness measurements. Analyses results of injection moulding experiments Tables 5, 6, 7 confirm the dominant influence of injection pressure (Rank 1) on mass and thickness.

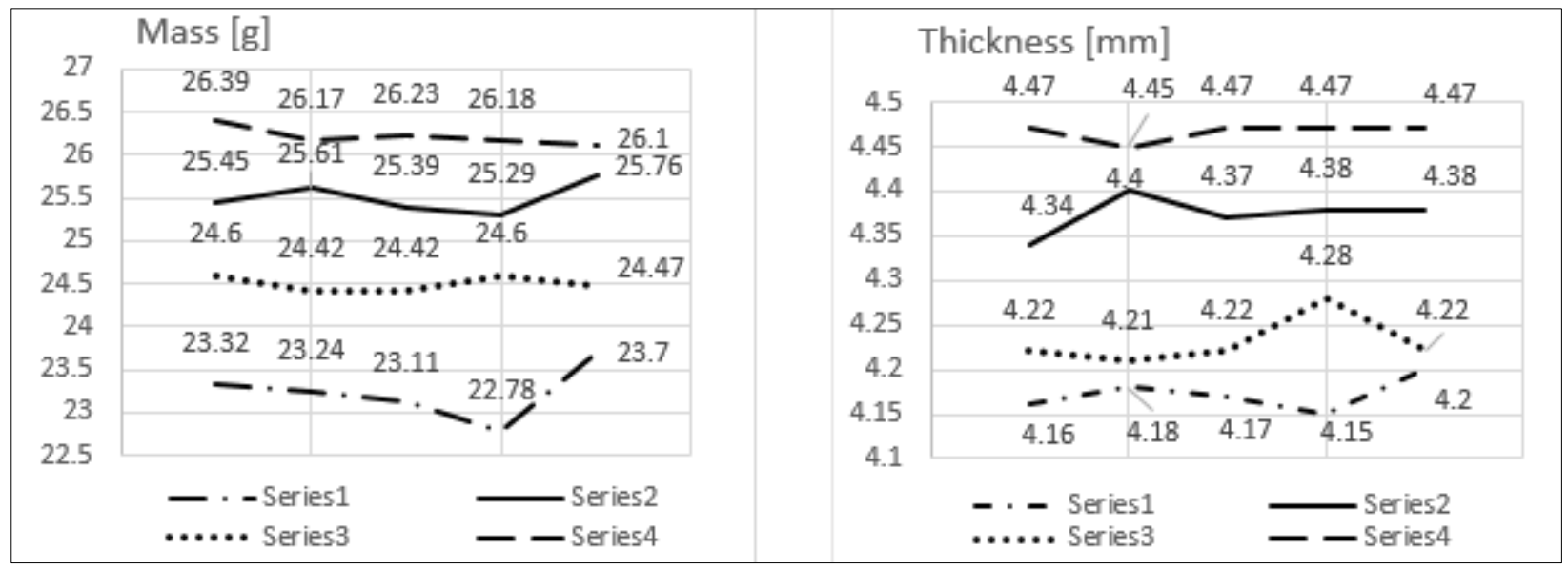

Figure 5. Mass and thickness measurements

Table 5. Mass measurements, mean sum of squares deviation, $S N$ ratio for larger-the-better

\begin{tabular}{|c|c|c|c|c|c|c|c|c|c|c|}
\hline \multirow{2}{*}{ No. } & \multirow{2}{*}{$\begin{array}{c}T_{N}+T_{C} \\
{\left[{ }^{\circ} \mathrm{C}\right]}\end{array}$} & \multirow{2}{*}{$\begin{array}{c}p_{h} \\
\text { [bar] }\end{array}$} & \multirow{2}{*}{$\begin{array}{l}t_{H} \\
{[\mathrm{~s}]} \\
\end{array}$} & \multicolumn{5}{|c|}{ Mass Measurements $\left(y_{i}\right)[\mathrm{g}]$} & \multirow[b]{2}{*}{$M S D$} & \multirow[b]{2}{*}{$S N$ Ratio } \\
\hline & & & & 1 & 2 & 3 & 4 & 5 & & \\
\hline 1 & $320+70$ & 100 & 4 & 23.32 & 23.24 & 23.11 & 22.78 & 23.7 & 0.00185403 & 27.318833 \\
\hline 2 & $320+70$ & 130 & 8 & 25.45 & 25.61 & 25.39 & 25.29 & 25.76 & 0.001538066 & 28.13025068 \\
\hline 3 & $340+80$ & 100 & 8 & 24.6 & 24.42 & 24.42 & 24.6 & 24.47 & 0.001665757 & 27.7838847 \\
\hline 4 & $340+80$ & 130 & 4 & 26.39 & 26.17 & 26.23 & 26.18 & 26.1 & 0.001455296 & 28.3704872 \\
\hline
\end{tabular}


Table 6. Taguchi analyse on SN ratio for larger-the-better, mass measurements

\begin{tabular}{|c|c|c|c|c|c|c|c|}
\hline \multicolumn{2}{|c|}{ Factors } & \multicolumn{2}{|c|}{ Temperatures $T_{N}+T_{C}\left[{ }^{\circ} \mathrm{C}\right]$} & \multicolumn{2}{|c|}{ Injection Pressure $p_{h}$ Bar] } & \multicolumn{2}{|c|}{ Holding time $t_{H}[\mathrm{~s}]$} \\
\hline Exp. & SN Ratio & $320+70$ & $340+80$ & 100 & 130 & 4 & 8 \\
\hline 1 & 27.3188 & 27.3188 & & 27.3188 & & 27.3188 & \\
\hline 2 & 28.1303 & 28.1303 & & & 28.1303 & & 28.1303 \\
\hline 3 & 27.7839 & & 27.7839 & 27.7839 & & & 27.7839 \\
\hline 4 & 28.3705 & & 28.3705 & & 28.3705 & 28.3705 & \\
\hline \multicolumn{2}{|c|}{ Sum of $S N$ at level } & 55.4491 & 56.1544 & 55.1027 & 56.5007 & 55.6893 & 55.9141 \\
\hline \multicolumn{2}{|c|}{ Factor Effect at level } & 27.7245 & 28.0772 & 27.5514 & 28.2504 & 27.8447 & 27.9571 \\
\hline \multicolumn{2}{|c|}{ Factor Effect } & \multicolumn{2}{|c|}{0.3526} & \multicolumn{2}{|c|}{0.6990} & \multicolumn{2}{|c|}{0.1124} \\
\hline \multicolumn{2}{|c|}{ Rank } & \multicolumn{2}{|c|}{2} & \multicolumn{2}{|c|}{1} & \multicolumn{2}{|c|}{3} \\
\hline
\end{tabular}

Table 7. ANOVA analyse of sum of squares (SS), factors contribution, factor influence on mass

\begin{tabular}{|c|c|c|c|c|c|c|c|}
\hline Factors & Level 1 & Level 2 & $S N$ at L1 & $S N$ at L2 & SS & Contribution & Influence \\
\hline$T_{N}+T_{C}\left[{ }^{\circ} \mathrm{C}\right]$ & $320+70$ & $340+80$ & 27.72454184 & 28.07718595 & 0.124357871 & $19.9 \%$ & DOMINANT \\
\hline$p_{h}[\mathrm{bar}]$ & 100 & 130 & 27.55135885 & 28.25036894 & 0.488615105 & $78.1 \%$ & DOMINANT \\
\hline$t_{H}[\mathrm{~s}]$ & 4 & 8 & 27.8446601 & 27.95706769 & 0.012635466 & $2.0 \%$ & Negligible \\
\hline
\end{tabular}

\subsection{Electrical conductivity}

The electrical resistance is a direct indicator of the electrical conductivity, and on the layout presented in Figure 2, the resistance was calculated with Ohm's law. For the composite polypropylene-graphitecarbon black bipolar plates, the packing pressure influence on the conductivity was anticipated by reducing the graphite particles' gaps. The carbon black and graphite contribution were recorded. Nevertheless, in this particular situation, from Tables 8, 9 and 10, it can be observed a more considerable influence on the electrical conductance of the combined factor material temperature - mould temperature (Rank 1) versus the influence of the injection pressure (Rank 2). The temperature favours the contact between the graphite conductive particles penetrating the polymer layer, creating more electrically conductive circuits.

Table 8. Conductance $\mathrm{G}$ (calculated as $1 / \mathrm{R}$ ), mean sum of squares of reciprocals, $\mathrm{SN}$ ratio

\begin{tabular}{|c|c|c|c|c|c|c|c|c|c|c|}
\hline \multirow{2}{*}{ No. } & \multirow{2}{*}{$T_{N}+T_{C}$} & $p_{h}$ & \multirow{2}{*}{$t_{H}$} & \multicolumn{5}{|c|}{ Conductance, $G=1 / R[\mathrm{~S}]$} & \multirow{2}{*}{ MSD } & \multirow{2}{*}{$S N$ Ratio } \\
\cline { 6 - 9 } & {$\left[{ }^{\circ} \mathrm{C}\right]$} & {$[\mathrm{bar}]$} & {$[\mathrm{s}]$} & 1 & 2 & 3 & 4 & 5 & & \\
\hline 1 & $320+70$ & 100 & 4 & 1.96 & 2.56 & 2.78 & 3.33 & 3.03 & 0.14814 & 8.2933 \\
\hline 2 & $320+70$ & 130 & 8 & 2.78 & 3.33 & 3.03 & 3.70 & 3.23 & 0.0995 & 10.0218 \\
\hline 3 & $340+80$ & 100 & 8 & 3.70 & 4.17 & 4.17 & 4.76 & 4.17 & 0.05796 & 12.3687 \\
\hline 4 & $340+80$ & 130 & 4 & 4.17 & 4.76 & 4.76 & 5.00 & 4.55 & 0.04684 & 13.2938 \\
\hline
\end{tabular}

Table 9. Taguchi analyse on $S N$ Ratio for larger-the-better, conductance $(G=1 / R)$

\begin{tabular}{|c|c|c|c|c|c|c|c|}
\hline \multicolumn{2}{|c|}{ Factors $\rightarrow$} & \multicolumn{2}{|c|}{ Temperature $T_{N}+T_{C}\left[{ }^{\circ} \mathrm{C}\right]$} & \multicolumn{2}{|c|}{ Injection Pressure $p_{h}$ [bar] } & \multicolumn{2}{|c|}{ Holding Time $t_{H}[\mathrm{~s}]$} \\
\hline Exp. & SN Ratio & $320+70$ & $340+80$ & 100 & 130 & 4 & 8 \\
\hline 1 & 27.3188 & 8.2933 & & 8.2933 & & 8.2933 & \\
\hline 2 & 28.1303 & 10.0218 & & & 10.0218 & & 10.0218 \\
\hline 3 & 27.7839 & & 12.3687 & 12.3687 & & & 12.3687 \\
\hline 4 & 28.3705 & & 13.2938 & & 13.2938 & 13.2938 & \\
\hline \multicolumn{2}{|c|}{ Sum of $S N$ at level } & 18.3150 & 25.6625 & 20.6620 & 23.3156 & 21.5871 & 22.3905 \\
\hline \multicolumn{2}{|c|}{ Factor Effect at level } & 9.1575 & 12.8313 & 10.3310 & 11.6578 & 10.7936 & 11.1952 \\
\hline \multicolumn{2}{|c|}{ Factor Effect } & \multicolumn{2}{|c|}{3.6738} & \multicolumn{2}{|c|}{1.3268} & \multicolumn{2}{|c|}{0.4017} \\
\hline \multicolumn{2}{|c|}{ Rank } & \multicolumn{2}{|c|}{1} & \multicolumn{2}{|c|}{2} & \multicolumn{2}{|c|}{3} \\
\hline
\end{tabular}


Seres indicated the effect of temperatures on the specific volume and the product's packing [2]. Rosato et al. mentioned that melt temperatures help molecular knitting and entanglement, and mould temperature elevation promotes slow cooling, more time for packing, allowing the molecules to entangle [16]. On the other hand, with higher temperatures, the polymer permits conductive particles to create more conductive network chains, therefore better conductivity. Further experiments demonstrated a variance of the electrical resistance with the load and the contact surface quality.

Table 10. ANOVA analyse, sum of squares (SS), contribution, influence on conductance $G$

\begin{tabular}{|c|c|c|c|c|c|c|c|}
\hline Factors & Level 1 & Level 2 & $S N$ at L1 & $S N$ at L2 & SS & Contributio & Influence \\
\hline$T_{N}+T_{C}\left[{ }^{\circ} \mathrm{C}\right]$ & $320+70$ & $340+80$ & 9.157522895 & 12.83127368 & 13.49644486 & $87.5 \%$ & DOMINANT \\
\hline$p_{h}[\mathrm{bar}]$ & 100 & 130 & 10.33099641 & 11.65780016 & 1.760408191 & $11.4 \%$ & DOMINANT \\
\hline$t_{H}[\mathrm{~s}]$ & 4 & 8 & 10.79355387 & 11.19524271 & 0.161353929 & $1.0 \%$ & Negligible \\
\hline
\end{tabular}

\subsection{Fuel cell performance}

The measurement of the fuel cell efficiency equipped with the bipolar plates of the four experiments directly indicates the influence of the injection moulding parameters. Four bipolar plates of each experiment were assembled in a hydrogen-air (forced) fuel cell stack, as shown in Figure 6. The fuel cell stack was tested at room temperature.

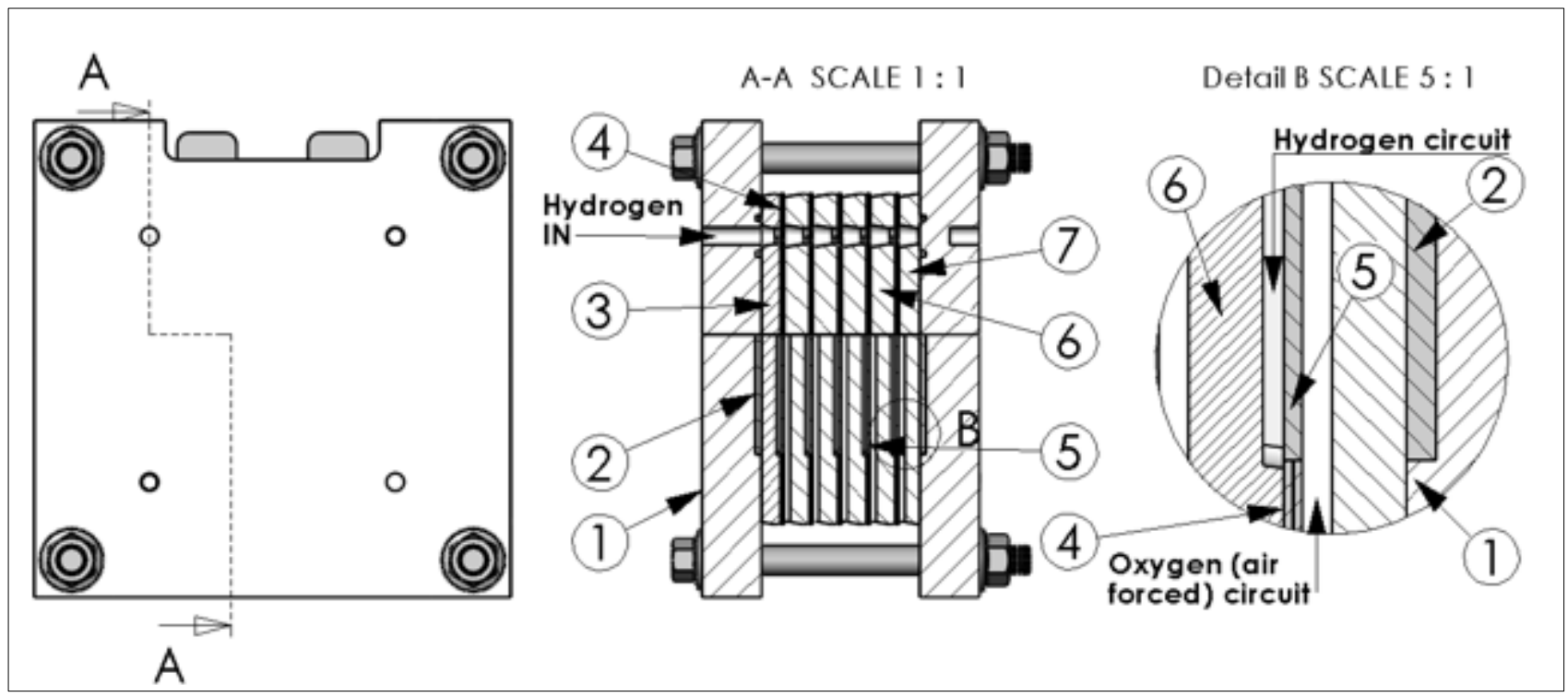

Figure 6. PEM (Proton-Exchange Membrane) Fuel cell test assembly: 1) Endplate Anode side;

2) Copper Collector; 3) Anode Endplate; 4) Gasket; 5) Polymer Membrane Electrode Assembly;

6) Bipolar Plate; 7) Cathode Endplate

Table 11. The power efficiency of the fuel cell with each of the four experiments bipolar plates

\begin{tabular}{|c|c|c|c|c|c|c|c|}
\hline Nr. & $\begin{array}{c}T_{N}+T_{C} \\
{\left[{ }^{\circ} \mathrm{C}\right]}\end{array}$ & $\begin{array}{c}p_{h} \\
{[\mathrm{bar}]}\end{array}$ & $t_{H}[\mathrm{~s}]$ & $\begin{array}{c}\text { Voltage } \\
{[\mathrm{V}]}\end{array}$ & $\begin{array}{c}\text { Current } \\
{[\mathrm{A}]}\end{array}$ & $\begin{array}{c}\text { Power } \\
{[\mathrm{W}]}\end{array}$ & $\begin{array}{c}\text { Power } \\
\text { Efficiency }\end{array}$ \\
\hline 1 & $320+70$ & 100 & 4 & 2.6855 & 0.8738 & 2.3466 & $100.00 \%$ \\
\hline 2 & $320+70$ & 130 & 8 & 2.6457 & 1.0108 & 2.6895 & $114.61 \%$ \\
\hline 3 & $340+80$ & 100 & 4 & 2.8053 & 1.0221 & 2.8642 & $122.06 \%$ \\
\hline 4 & $340+80$ & 130 & 8 & 2.8495 & 1.0994 & 3.1408 & $133.84 \%$ \\
\hline
\end{tabular}

As shown in Table 11, the power efficiency measurements confirmed the influence of melt and mould temperatures on the bipolar plates' performance and the fuel cell stack accordingly. According to 
our knowledge, not many works have been analysing process temperatures affecting the conductivity of a product injection moulded in a polymeric composite with high inorganic filler content. The dominant influence of temperatures on the electrical resistance shown in Table 10 agrees with Lellinger et al. [30], Chandra et al. [31], Rios et al. [32], all confirmed the significant effect of increasing melt temperature on decreasing the electrical resistivity. For example, Chandra et al. found the electrical conductivity 3.84 E-06 S/cm of an injection moulded composite CNT 1.8wt\% / PC at low injection speed and low process temperature and $1.81 \mathrm{E}-05 \mathrm{~S} / \mathrm{cm}$ at high injection speed and high level of process temperature [31]. On injection moulding of polycarbonate filled with $5 \%$ carbon nanotubes, Rios et al. demonstrated an increase in the processing temperature from 280 to $310^{\circ} \mathrm{C}$ led to a decrease of about two orders magnitude the volumetric resistivity [32].

\subsection{Analyses of inorganic content influence on viscosity and injection pressure}

As presented in 2.3 with Dobrescu et al. formula (1), for values of $a=0.0295$ and $b=1.3$ [10] can be estimated a relative composite's viscosity $\eta_{k}$ :

$$
\eta_{k}=\eta_{p}\left(1+a c^{b}\right)=\eta_{p}\left(1+0.0295 \cdot 85^{1.3}\right)=10.705 \cdot \eta_{p}
$$

To estimate the injection pressure, we used the formulas (2) and (3) proposed in this paper, considering the values recorded on the Polypropylene injection moulding experiments (set hydraulic injection pressure $p_{h p}$ of $30 \mathrm{bar}$, cavity pressure $220 \mathrm{bar}$, nozzle temperature of $220^{\circ} \mathrm{C}$ and a mould temperature of $30^{\circ} \mathrm{C}$ ):

$$
\begin{aligned}
& p_{h k}=p_{h p}\left(1+\frac{a c^{b}}{d^{f}}\right)=p_{h p}\left(1+\frac{0.0295 \cdot 85^{1.3}}{\left(\frac{330+75}{220+30}\right)^{2.5}}\right)=3.846 \cdot p_{h p} \\
& p_{h k}=3.846 \cdot p_{h p}=115.389[\mathrm{bar}]
\end{aligned}
$$

The equation fits the results if conditioned by an influence of the combined temperatures. It could be used as an estimated injection pressure level (hydraulic installation pressure multiplied by the intensification factor) in the design of the experiment, as shown in Table 3. Analysing the results, we noted that the cavity pressure is complex influenced by injection pressure, melt and mould temperatures and inorganic content, as shown in Table 12. The inorganic content negatively influences the flow, higher pressures, and necessary temperatures (experiment 5 / 1,2,3,4). Increasing the melt and mould temperatures reduces the injection pressure (experiment $2 / 4$ ).

Table 12. Set and measured hydraulic injection pressure - $p_{h}$, calculated specific injection pressure $p$, measured cavity pressure $-p_{c}$, average mass and average $G$ for injection moulding of composite $\mathrm{PP}+87 \mathrm{GR}$ and polypropylene PP, at different temperatures of barrel's nozzle $T_{N}$ and mould cavity $T_{C}$

\begin{tabular}{|c|c|c|c|c|c|c|c|}
\hline $\begin{array}{c}\text { Exp. } \\
\text { No. }\end{array}$ & Material & $T_{N}+T_{C}\left[{ }^{\circ} \mathrm{C}\right]$ & $\begin{array}{c}p_{h}[\mathrm{bar}] \\
\text { Set \& measured }\end{array}$ & $\begin{array}{c}p[\mathrm{bar}] \\
\text { calculated }\end{array}$ & $\begin{array}{c}p_{c}[\mathrm{bar}] \\
\text { measured }\end{array}$ & Average mass [g] & $\begin{array}{c}A v \cdot G \\
(=1 / R) \\
{[\mathrm{S}]}\end{array}$ \\
\hline 1 & PP+87GR & $320+70$ & 100 & 807.41 & 98.6 & 23.23 & 2.733 \\
\hline 2 & PP+87GR & $320+70$ & 130 & 1049.63 & 189 & 25.5 & 3.214 \\
\hline 3 & PP+87GR & $340+80$ & 100 & 807.41 & 187.75 & 24.502 & 4.193 \\
\hline 4 & PP+87GR & $340+80$ & 130 & 1049.63 & 300.125 & 26.214 & 4.647 \\
\hline 5 & PP & $220+30$ & 30 & 242.22 & 207.6 & 10.8 & - \\
\hline
\end{tabular}

Increasing the melt and mould temperatures helps obtain better replication by obtaining higher cavity pressure at the same injection pressure level (experiment 3/1. Results confirm that an accurate rheologic description of the composite is a must for an appropriate flow simulation, and the process temperatures influence the product's proprieties. When not available, or optimising the process parameters through simple design experiments, the suggested formula might help. 
Brydson demonstrated the melt viscosity is a function of the difference between the polymer's processing temperature and glass transition temperature $\left(T-T_{g}\right)$ and claimed an increase in pressure with 1000 bar is equivalent to a drop in temperature in the range of $30-50^{\circ} \mathrm{C}$ [1]. As shown in Table 12 , at the same injection pressure $p_{h}$ of 100 bar, specific pressure $p$ of 807.41 bar respectively, a combined increase of temperatures with $30^{\circ} \mathrm{C}$ increased the mould cavity $p_{c}$ from 98.6 to 187.75 bar (Experiment $1 / 3$ ), and at pressure $p_{h}$ of $130 \mathrm{bar}, p$ of $1049.63 \mathrm{bar}$, a combined increase of $30^{\circ} \mathrm{C}$ increased the mould cavity $p_{c}$ from 189 to 300 bar (Experiment 2/4). The polypropylene injection moulding has a different flow behaviour than the polypropylene-graphite composite, with a lower cavity pressure drop.

Electrical conductivity can be predicted on a complex model considering the content, dimensions, and orientation of the conductive particles in the polymeric matrix. Table 12 results indicate that the process temperatures and the cavity pressure, which contribute too, can be considered for an estimation.

\section{Conclusions}

The Taguchi and ANOVA analysis on an L4 orthogonal array demonstrated a dominant influence of injection pressure on the mass and thickness of the bipolar plate, a situation that was anticipated. Furthermore, an adapted formula has been introduced here for estimating the injection pressure by considering the influence of the combined temperatures of the melt (at the barrel nozzle) and mould temperature. The bipolar plates were tested in a PEM hydrogen fuel cell stack, a direct indication of the influence of injection moulding parameters on the performance. The Taguchi Method does not require high-level mathematics and, backed by a complete knowledge of the technology underlying principles, can be integrated even by small companies.

The electrical resistance analysis evidenced a significant influence of composite and mould temperatures, explained by better contact of the electrically conductive particles through the polypropylene's melted layer. In addition, higher process temperatures contributed to increased cavity pressure and better packing and conductivity by improving the conductive network chain. The electrical conductivity can be predicted by a model considering the process temperatures influence.

The material's excellent proprieties are not a guarantee that the manufactured product will correspond to the requirements. Moreover, the experiments demonstrated the need to optimise the injection moulding parameters to get the best performance of the composite recipe. The efficiency of a hydrogen-air fuel cell stack assembled with each of the four bipolar plates demonstrated the dominant temperature's (rank 1) and injection pressure's (rank 2) effect for better performance.

Acknowledgements: TGA Analyses were kindly provided by Paul Octavian Stanescu from Advanced Polymer Materials Group, Politehnica University of Bucharest. Alice Cristea from Revista Materiale Plastice kindly provided a digital copy of the paper [10]. The mould and experiments on equipment of LS INTEH s.r.l. Bucharest.

\section{References}

1.BRYDSON, J. A., Plastics Materials, Fifth Edition, ISBN 0-408-00721-4, London, 1989

2.SERES, I., Injectarea Materialelor Plastice, ISBN 973-97652-6-2, p.103, Oradea, 1996

3.BAUHOFER, W., KOVACS, J.Z. A review and analysis of electrical percolation in carbon nanotube polymer composites. Composites science and technology. 2009;69(10):1486-98.

4.DWEIRI R, SAHARI J. Electrical properties of carbon-based polypropylene composites for bipolar plates in polymer electrolyte membrane fuel cell (PEMFC). Journal of Power Sources. 2007;171(2):42432.

5.DERIETH, T., BANDLAMUDI, G., BECKHAUS, P., KREUZ, C., MAHLENDORF, F., HEINZEL, A. Development of highly filled graphite compounds as bipolar plate materials for low and high temperature PEM fuel cells. Journal of New Materials for Electrochemical Systems. 2008;11(1):21.

6.RZECZKOWSKI, P., KRAUSE, B., PÖTSCHKE, P. Characterization of highly filled PP/graphite composites for adhesive joining in fuel cell applications. Polymers. 2019 Mar;11(3):462. 
7.HALÁSZ, L., BELINA, K., SZÜCS, A. Thermal degradation of poly (olefin- $\alpha$ olefin) copolymers. In AIP Conference Proceedings 2014. Vol. 1593, No. 1, pp. 222-226.

8.CHIPARA, M., LOZANO, K., HERNANDEZ, A., CHIPARA, M., TGA analysis of polypropylenecarbon nanofibers composites. Polymer Degradation and Stability. 2008 Apr 1;93(4):871-6.

9.***Arburg Polytronica User Manual E050 033/0000 03/01 81100

10.DOBRESCU, V., DRĂGAN, Gh., GOLDENBERG, N., WOLF, B., The Influence of Carbon Black Type and Concentration upon the Properties of High and Low-Density Polyethylene. Part I. Rheological Properties - Paper presented at the National Congress of Chemistry, Bucharest, Sept. 11-14, 1978, Mater. Plast. 16(1), 1979, 49

11.ROY, R., A Primer on the Taguchi Method, ISBN 0-442-23729-4, p.8, New York, 1990

12.TAGUCHI, G., CHOWDHURY, S., WU, Y., Taguchi's Quality Engineering Handbook, ISBN 0471-41334-8, p.391, New Jersey, 2005

13.KULKARNI, S., Robust Process Development and Scientific Molding: Theory and Practice, ISBN 978-3-446-42275-9, p. 145, Munich, 2010

14.WHELAN, T., Injection Moulding Materials, e-ISBN-13: 978-94-009-7358-9, Essex, 1982

15.BRYCE, D. M., Plastic Injection Molding, Volume I - Manufacturing Process Fundamentals-Society of Manufacturing Engineers (SME), ISBN 0-87263-472-8, Dearborn, 1996

16.ROSATO, DOMINICK V., ROSATO, DONALD V., ROSATO, MARLENE G., Injection molding handbook, $3^{\text {rd }}$ ed., p.603, ISBN 978-1-4613-7077-2, New York, 2000

17.GOODSHIP, V., Practical Guide to Injection Moulding, ISBN 1-85957-444-0, Shawbury, 2004

18.GORDON, M. J., Total Quality Process Control for Injection Molding, ISBN 978-0-470-22963-7, Wiley, New Jersey, 2010

19.ZHOU, H., Computer Modeling for Injection Molding, ISBN 978-0-470-60299-7, 2013

20.LERMA VALERO, J. R., Plastics Injection Molding, ISBN 978-1-56990-689-7, Munich, 2020

21.SANDU, I-L., FETECAU, C., Effects of Injection Process Parameters on the Warpage of Thinwalled Plastic Parts, Mater. Plast. 48(4), 2011, 315

22.PACKIANATHER, M., GRIFFITHS, C., KADIR, W., Micro injection moulding parameter tuning, Procedia CIRP 33 (2015) 400 - 405

23.LO, CH., Analysis of injection molding for computer cooling fans by Taguchi method and grey relational analysis, Filomat 30:15 (2016), 4199-4211

24.WANG, J., HOPMANN, C., KAHVE, C., HOHLWECK, T, ALMS, J., Measurement of specific volume of polymers under simulated molding process, Materials and Design 196 (2020) 109136

25.*** knowledge.autodesk.com/support/moldflow-insight, retrieved 02.02.2020 10:30

26.***Arburg Selogica User Manual

27.***Engel CC100/200 User Manual

28.***Negri Bossi Dimiel 2 User Manual

29.***Fanuc Roboshot S2000-i

30.LELlingER, D., XU, D., OHNEISER, A., SKIPA, T. T., ALIG, I. Influence of the injection moulding conditions on the in-line measured electrical conductivity of polymer-carbon nanotube composites. physica status solidi (b), 245(10), 2008, pp.2268-2271.

31.CHANDRA, A., KRAMSCHUSTER, A., HU, X., and TUMG, L., Effect of injection molding parameters on the electrical conductivity of polycarbonate/carbon nanotube nanocomposite. In ANTECCONFERENCE PROCEEDINGS- Vol. 4, 2007, p. 2171.

32.RIOS, P. F., OPHIR, A., KENIG, S., EFRATI, R., ZONDER, L., POPOVITZ-BIRO, R. Impact of injection-molding processing parameters on the electrical, mechanical, and thermal properties of thermoplastic/carbon nanotube nanocomposites. Journal of Applied Polymer Science vol. 120, no. 1, 2011, pp. 70-78.

Manuscript received: 29.04 .2021 